\title{
Watch'n Listen \\ Effects of A Visual Approach on ESL Learner' Listening Comprehension in an ESL Context
}

\author{
Muhammad Asyraf Bin Khaja Mohideen \\ Faculty of Education \\ National University of Malaysia \\ Selangor, Malaysia.
}

\author{
Dr. Nur Ehsan Bin Mohd \\ Faculty of Education \\ National University of Malaysia \\ Selangor, Malaysia
}

\begin{abstract}
The proficiency of learners' listening comprehension will often determine their proficiency in other language skills. Listening skill has not be emphasized on in the previous Primary School Standard Curriculum. By implementing the New Educational Blueprint (2013-2025), the Malaysian Ministry of Education (MoE) is putting more emphasis on listening and speaking skills. The study was conducted a study to see the effects of having visual stimulus on the learners' listening comprehension during a listening task. Employing Kemmis and Mactaggart's model, the study was designed to be an action research project for the period of 2 weeks. A total of 47 participants, aged 9, from a primary school in Negeri Sembilan were recruited, comprising a control group $(n=22)$ and a treatment group $(n=25)$. A pretest was conducted for both the experimental and control group. After the pretest, the experimental group went through six intervention sessions in two weeks which took one hour per session. Based on the data analysis, the result shows that the experimental group outperformed the control group. The study suggests that the participants' listening comprehension improved with visual stimulus. Fellow educators can adapt the intervention used in this study to conduct listening comprehension tasks to ensure the efficiency of their lesson.
\end{abstract}

Keywords:- Listening skill, Listening comprehension, Audio text, Visual stimulus, ESL in Malaysia.

\section{INTRODUCTION}

With the implementation of the New Educational Blueprint, 2013 and CEFR, 2017, the Ministry of Education (MOE) is emphasizing on the importance of listening and speaking. Before the implementation of the New Educational Blueprint and CEFR, teaching and learning of the English Language primarily focused on reading and writing skill as those are the skills that are tested in formal exams such as UPSR, PT3 and SPM. CEFR is an international standard with six-point descriptive on language ability.

Listening is a very important skill to acquire in any language learning. Having a good listening skill can be very helpful for pupils to acquire the other language skills in the process of learning the language. Tindall and Nisbet(2008) defines listening as a process of comprehending what is heard. It also has an essential function in the process of learning. Burleson (2011) defines listening as a process of understanding a speech that speakers have transmitted in the effort to understand and react to them in a proper manner. Cahyaningrum (2010) describes listening as a multiple dimensions of understanding, focusing, analyzing and assessing spoken messages and responding to what is being said.

Listening is also an active process. According to Burkart (1998), listeners are usually actively involved in understanding a spoken message. In the process, listeners would bring in their background and linguistic knowledge to understand the message in an audio text or a spoken message. Listeners would activate their knowledge on phonology, grammar structure and also experiences in the process of perceiving an audio message. Brown (1996) mentioned that learning to listen in a language learning process cannot be overestimated. Listening plays an important role in everyday development and maintenance of social and personal relationships. In this study, we are trying to find methods and approaches that would ease learners in sharpening their listening skills. One of the method that we focused in this study is using visual stimulus to enhance listening comprehension.

After observing the efficiency of a few lessons focusing on listening task, the main author noticed that pupils are having trouble comprehending what they are listening to. This is a very troubling issue because this will affect their formative assessment performance. The implementation of the New Educational Blueprint further puts emphasis on the importance of mastering the listening and speaking skill. In this scenario, there are two problems that can be observed. The first problem is pupils are not used to listening and speaking in English compared to reading and writing. The second problem is teachers are not fully equipped to teach effectively teach the two skills. In this study we will focus on the second problem. We intend to explore the methods and approaches in which teachers can use to apply in their lesson. 


\section{LITERATURE REVIEW}

We will now look into the definitions and past studies done on the variables which are visual stimulus and listening comprehension. Visual stimulus can be defined as the presentations of images or videos to assist the teaching and learning process. For this study, we will focus on using pictures as visual stimulus that will be used in teaching listening comprehension.

\section{A. Visual Stimulus}

Arjulayana (2018) carried out a qualitative descriptive research on using videos in listening lessons. Based on the data collected, it was concluded that most of the students find listening tasks boring and dull. However after introducing the idea of using videos in listening lessons, students see listening as a more enjoyable lesson. Arjulayana also reported that the students found it easier to understand English conversations when there is a video presented.

Arono (2014) also conducted a similar research where he focused on the assistance of multimedia in teaching listening. Based on the pretest and posttest scores gathered, the results of the median of the experimental group increased from 58.12 in the pretest to 77.81 in the posttest. The difference of median for the control group is 56.93 in the pretest and 58.42 in the post test. This proves that the assistance of multimedia is really effective in teaching listening.

Another study conducted by Nachoua (2012) focused on improving students' listening skill with ComputerAssisted Language Learning. The results gathered shows that students that are exposed to an aural and visual environment are often active and motivated learners. A similar study was conducted by Sejdiu(2017). From the study, it was concluded that the Computer-Assisted Language Learning program is a very efficient mean to develop and enhance listening skills.

\section{B. Listening Comprehension}

Listening comprehension can be defined as the ability to understand the meaning of a spoken message. Brown and Yule (1983) defined listening comprehension as something a person would be able to understand from what is heard. Listening comprehension also means understanding speech, understanding spoken language, recognizing speech and perceiving speech (Dirven \& Oakeshott-Taylor,1984). Morley and Lawrence (1971) has set a few principles of teaching listening comprehension. The principles are as followed:

$>$ A definite and clear goal should be stated.

$>$ Procedures should be carefully planned.

$>$ Learners should actively participate in listening comprehension lessons.

$>$ A communicative necessity should be provided to prompt memory.

$>$ Emphasis should be on memory work.

$>$ Listening comprehension should be taught not tested.
According to Arjulayana (2018), there are five elements of listening comprehension which are hearing, attending, understanding, responding and remembering. There are a few studies conducted on listening comprehension. Borzogian (2012) conducted a correlation analysis to determine whether listening skill was correlated with the language proficiency as a whole. From the study, it was concluded that listening skill has a $90 \%$ correlation with overall language proficiency. This means that the higher the listening skill proficiency, the higher the students' performance in the overall IELTS score. Abdalhamid (2012) conducted a study on listening comprehension strategies. The participants were asked to sit for a test and complete a questionnaire on the strategies they used in answering the questions in the test. From the study, it was concluded that both intermediate and advanced group used metacognitive, cognitive and socioeffective strategies in answering the listening comprehension questions.

\section{METHOD}

A. Aim

To study the effects of having a visual stimulation with audio text on learners' listening comprehension.

\section{B. Objective}

To identify the effectivenesss of using visual stimulus in teaching listening comprehension.

\section{Research Question}

Do visual stimuli help participants to improve their listening comprehension?

\section{Research Design}

A practical action research design will be used to conduct this study. This is suitable for the intended study as the research is carried out by a teacher researcher on his teaching practice with his own pupils. According to Cresswell 202), action research aims to improve specific and local issues. Educators are usually involved in action research to study problems concerning their own teaching practice. The Kemmis and Mctaggart Model for action research is adapted to help navigate the study.

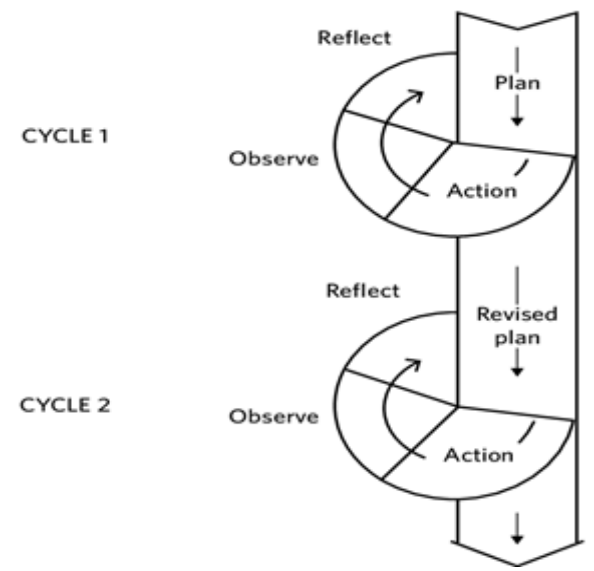

Fig 1:- Kemmis and Mctaggart's Model of Action Research. 
In this research, the first cycle was a pilot study. Then the plan was revised to accommodate the second cycle which is the main study. As we can see in diagram 1, there are 4 stages in the model used which are planning, acting, observing and reflecting. In the planning stage, a critically informed action plan is developed to recuperate what is happening in the lessons. In the action stage, the implementation plan is executed. After the action stage, the effects of the action plan are observed. Finally, the effects of the action plan are reflected on.

\section{E. Procedures}

In the planning stage, researcher noticed that pupils had trouble in completing listening comprehension task. Pupils were unable to answer comprehension questions because they were having a hard time following and understanding the audio text. Then the researcher used the Kemmis and Mctaggart model of action research to plot and navigate the course of the research. Next is the implementation of the intervention. Before the intervention is implemented, the participants sat for a pretest, where they would have to answer 6 listening comprehension questions by listening to an audio text. After the pretest, the experimental group will go through 6 sessions with the intervention. In each of the sessions, pupils are required to answer 6 listening comprehension questions by listening to the audio text and observing the picture slides shown. After that, participants of the experimental and control group will sit for a post test. The scores for pretest, posttest and each intervention sessions are collected and analysed. Based on the data analysis, a conclusion was made on whether the intervention really helped pupils improve their listening comprehension skill.

\section{F. Instruments}

There are two instruments that is used to collect the necessary data from the study. The instruments are tests that were used before and after the intervention, and the participants score during the intervention sessions. The test consists of six comprehension questions. Participants are required to listen to the audio text and answer all of the questions. Questions one to four requires participants to write the answers and questions five and six

\section{G. Participants}

This study was conducted in a Federal Lang Development Authority (FELDA) settlement. A total of 47 pupils participated in this study. The pupils are from two classes of the same schooling year. All of them are in Year 3 , therefore, they are 9 years old. 25 participants from the same class are in the experimental group where they went through six intervention sessions and the remaining 22 participants are in the control group where they did not go through the intervention sessions. All the participants for this study come from a low to mid income families. A majority of the participants have low English language proficiency.

\section{RESULTS AND DISCUSSIONS}

\section{A. Pretest and Post Test Results}

The Mean mode and median of the pretest and post test results were calculated using the SPSS software and the table below shows the data.

\begin{tabular}{|c|c|c|c|}
\hline \multicolumn{4}{|c|}{ Experimental Group } \\
\hline \multicolumn{2}{|c|}{} & Pretest & Posttest \\
\hline \multirow{2}{*}{$\mathrm{N}$} & Valid & 25 & 25 \\
\cline { 2 - 4 } & Missing & 0 & 0 \\
\hline \multicolumn{2}{|c|}{ Mean } & 3.6800 & 5.0000 \\
\hline \multicolumn{2}{|c|}{ Median } & 3.0000 & 5.0000 \\
\hline \multicolumn{2}{|c|}{ Mode } & 3.00 & 5.00 \\
\hline
\end{tabular}

Table 1 Group.

Mean, Mode And Median Of The Experimental

The table above shows the mean, mode and median calculated for the pretest and posttest of the experimental group. From the table, we can see that there is an improvement in the mean of the scores which increased from 3.68 to 5.00 . The mode score of the pretest is 3.00 which increased to 5.00. The same goes to the median as well. There is an increase from 3.00 in the pretest to 5.00 in the post test.

\begin{tabular}{|c|c|c|c|}
\hline \multicolumn{4}{|c|}{ Control Group } \\
\hline \multicolumn{2}{|c|}{} & PretestC & PosttestC \\
\hline \multirow{2}{*}{$\mathbf{N}$} & Valid & 22 & 22 \\
\cline { 2 - 4 } & Missing & 3 & 3 \\
\hline \multicolumn{2}{|c|}{ Mean } & 3.0000 & 3.0909 \\
\hline \multicolumn{2}{|c|}{ Median } & 3.0000 & 3.0000 \\
\hline \multicolumn{2}{|c|}{ Mode } & 3.00 & 3.00 \\
\hline
\end{tabular}

Table 2

\section{Mean, Mode And Median Of The Control Group.}

The table above shows the mean, mode and median calculated for the pretest and posttest of the control group. From the table, we can see that there is an improvement in the mean of the scores which increased from 3.00 to 3.09. The mode score of the pretest is 3.00 which remained in the post test. The same goes to the median as well. The median score is the same for both the pretest and posttest.

From this we can conclude that the intervention does help in improving the participants listening comprehension. As we can see in the data, there is a difference in the mean, mode and median of the pretest and posttest for the experimental group whereas there very little to no difference in the mean, mode, and median for the control group. This means that the treatment of intervention has a significant effect on the participants listening comprehension. 


\begin{tabular}{|c|c|c|c|c|c|}
\hline & Groups & N & Mean & $\begin{array}{c}\text { Std. } \\
\text { Dev. }\end{array}$ & $\begin{array}{c}\text { Std. } \\
\text { Error } \\
\text { Mean }\end{array}$ \\
\hline Posttest & Exp. & 25 & 5.000 & .8165 & .1633 \\
\cline { 2 - 6 } & Control & 22 & 3.091 & .6838 & .1458 \\
\hline
\end{tabular}

Table 3

\section{Group Statistic}

\begin{tabular}{|c|c|c|c|}
\hline & & $\begin{array}{c}\text { Equal } \\
\text { Varrianes } \\
\text { assumed }\end{array}$ & $\begin{array}{c}\text { Equal } \\
\text { Variances } \\
\text { not } \\
\text { assumed }\end{array}$ \\
\hline \multicolumn{2}{|l|}{$\mathrm{t}$} & 8.622 & 8.72 \\
\hline \multicolumn{2}{|c|}{$\mathrm{df}$} & 45 & 44.90 \\
\hline \multicolumn{2}{|c|}{ Sig.2-tailed } & .000 & .000 \\
\hline \multicolumn{2}{|c|}{ Mean Difference } & 1.90909 & 1.90909 \\
\hline \multicolumn{2}{|c|}{ Std. error difference } & .22142 & .21890 \\
\hline \multirow{2}{*}{$\begin{array}{l}95 \% \text { confidence } \\
\text { Interval of } \\
\text { Difference } \\
\end{array}$} & Lower & 1.4632 & 1.46817 \\
\hline & Upper & 2.35506 & 2.500 \\
\hline
\end{tabular}

Table 4

\section{Independent Samples T-Test Spss Analysis}

The tables 3 and 4 above shows the results of the independent sample t-test analysis of the post test data from the experimental and control group. The independent sample t-test was conducted to compare posttest scores of the experimental group and the control group. From the output of the test, we can see that there was a significant difference in the scores for experimental group ( $\mathrm{M}=5.00$, $\mathrm{SD}=0.82)$ and control group $(\mathrm{M}=3.1, \mathrm{SD}=0.68)$ conditions; $\mathrm{t}(8.2)=8.6, \mathrm{p}=0.00$. The $P$ value of the independent $\mathrm{t}$-test is 0.00 . The $\alpha$ value that is taken for this test is $\alpha<0.5$. Since the $P$ value is less that $\alpha$ value, the hypothesis is accepted. There is a significant difference in posttest scores of the experimental group and the control group.

\section{B. Intervention Sessions}

During each of the intervention sessions, participants' scores were collected. The scores were collected to see the participants' progress by comparing the scores they acquire for each of the sessions. The data was collected from the experimental group only as the participants from the experimental group are the only ones that goes through these sessions.

\begin{tabular}{|c|c|c|c|c|c|c|}
\hline \multirow{2}{*}{ Participants } & \multicolumn{6}{|c|}{ Score in Intervention sessions } \\
\cline { 2 - 7 } & S1 & S2 & S3 & S4 & S5 & S6 \\
\hline P1 & 3 & 3 & 5 & 4 & 5 & 6 \\
\hline P2 & 6 & 5 & 5 & 6 & 5 & 6 \\
\hline P3 & 5 & 6 & 5 & 4 & 3 & 4 \\
\hline P4 & 6 & 6 & 5 & 6 & 5 & 6 \\
\hline P5 & 5 & 5 & 4 & 5 & 4 & 5 \\
\hline P6 & 6 & 5 & 4 & 5 & 6 & 6 \\
\hline P7 & 4 & 5 & 4 & 4 & 5 & 5 \\
\hline P8 & 6 & 5 & 5 & 4 & 4 & 3 \\
\hline P9 & 6 & 5 & 5 & 5 & 5 & 4 \\
\hline P10 & 2 & 4 & 3 & 3 & 4 & 4 \\
\hline P11 & 4 & 4 & 4 & 3 & 3 & 4 \\
\hline
\end{tabular}

ISSN No:-2456-2165

\begin{tabular}{|l|l|l|l|l|l|l|}
\hline P12 & 6 & 6 & 5 & 4 & 5 & 5 \\
\hline P13 & 6 & 6 & 6 & 5 & 6 & 6 \\
\hline P14 & 4 & 5 & 5 & 4 & 3 & 3 \\
\hline P15 & 3 & 4 & 3 & 4 & 4 & 4 \\
\hline P16 & 2 & 3 & 4 & 5 & 4 & 4 \\
\hline P17 & 3 & 3 & 2 & 3 & 4 & 4 \\
\hline P18 & 5 & 6 & 6 & 5 & 6 & 6 \\
\hline P19 & 6 & 6 & 5 & 5 & 6 & 6 \\
\hline P20 & 5 & 6 & 4 & 5 & 5 & 6 \\
\hline P21 & 6 & 6 & 5 & 6 & 5 & 6 \\
\hline P22 & 2 & 4 & 3 & 4 & 3 & 2 \\
\hline P23 & 6 & 6 & 5 & 5 & 6 & 6 \\
\hline P24 & 5 & 6 & 5 & 5 & 6 & 6 \\
\hline P25 & 6 & 6 & 5 & 5 & 6 & 6 \\
\hline
\end{tabular}

Table 5:- Score for Intervention Sessions.

The table above shows the scores obtained by participants in the intervention sessions. From the table, we can see some increases as well as decreases in each session. Generally, most of the participants' score increases after each sessions. a very minute number of participants' score decreases from one session to the other. This data is used to show that generally, the use of visual stimulus with audio text is effective in a listening comprehension task. Participants are able to comprehend what they listen to by watching what is shown on the board. With time, the participants are familiar with the concept of listening comprehension and they know how to listen for main ideas and understand the audio text.

Listening comprehension is one of the most challenging task in language learning. From the above, it is can be seen that learners do face difficulties in listening tasks. It is a complex skill and therefore educators need to incorporate various methods to ease through the listening tasks to enable learners to learn in a fun and interesting way.

The intervention was aimed to develop participants' ability in comprehending the audio text. The strategy used in the intervention is the use of visual stimulus while participants listen to the audio text. In this study, the visual stimuli used are pictures. From the data gathered and analysed above, we can see that participants were able to understand the mechanics of listening comprehension. This means that the author's initial assumption on the usage of visual stimuli would improve participants' listening comprehension was correct. The aim of the study was achieved effectively. This is further supported by a study conducted by Arono (2014). In Arono's study, an increase of median score in the post test could be seen. His study proves that the assistance of multimedia is really effective in teaching listening. The use of visual stimuli can really change the participants' perception of listening activities as something that is boring and dull to something more enjoyable. Arjulayana (2018) concluded in a study that pupils enjoy listening tasks when the audio text is accompanied by a video. 
From the results and statistical analysis, we can say that participants from the experimental group performed better than the control group. In the posttest, most of the participants were able to score 5 and 6 out of 6 after been given the treatment. This is further supported by the scores obtained in the intervention sessions where most of the participants showed progress throughout the six sessions. The drop of scores in might be caused by some other factors or distractions as the participants were able to get a high score in the first few sessions. In conclusion, we can say that there are improvements in participants' listening comprehension skills when we use a visual stimulus to accompany the audio text.

\section{IMPLICATION AND CONCLUSION}

As discussed earlier, this study was conducted to observe the effects of using visual stimulus on participants' listening comprehension. With the data collected, we can see that it is easier for participants to comprehend listening texts with visual stimulus. This can be adapted into a variety of listening tasks. This study can be further extended into other areas of listening skills. Teachers can use this research as a guide to experiment with the concept for other purposes of listening. Other than that, teachers can also experiment with other types of visual stimulus such as videos, animations puppets and models for listening comprehension lessons. The use of visual stimulus is highly recommended in assisting participants listening comprehension especially when the participants have low language proficiency. Finally, from the result and discussion, we can conclude that there is a significant difference in the marks between the participants who went through the treatment and those who did not. The difference in mean, mode and median for the post test score of the experimental group and the control group is vastly different. This suggests that the use of visual stimulus is effective in the teaching of listening comprehension.

\section{REFERENCES}

[1]. Tindall, E. and Nisbet, D. 2008. Listening: A vital skill for learning. International Journal of Learning. 15(6):121- 128

[2]. Burleson, B. 2011. A constructivist approach to listening. International Journal of Listening, 25(1-2) 27-46.

[3]. Cahyaningrum, D. 2010. The Effectiveness Of Using Video In Teaching Listening Of Oral Narrative Text. English Department. Teacher Training And Education Faculty. Sebelas Maret University. Surakarta

[4]. Burkart, G S. 1998. Modules for the Professional Preparation Of Teaching Assistants In Foreign Languages Washington, DC: Center for Applied Linguistics.

[5]. Brown, D. 1994. Teaching by Principles. New Jersey: Prentice Hall

[6]. Brown, G. and Yule, G. 1983. Teaching Listening Comprehension. Teaching The Spoken Language. Cambridge, Cambridge University Press.
[7]. Ministry of Education. (2015). Executive Summary Malaysia Education Blueprint 2013-2025 (Preschool to Post-Secondary Education).

[8]. Arjulayana. 2018. The Use Of Video In Teaching Listening Skill. Globishan English-indonesian journal for English, education and culture). 6(1).

[9]. Arono. 2014. Improving Students Listening Skill Through Interactive Multimedia In Indonesia. Journal Of Language Teaching And Research. 5(1). 63-69.

[10]. Nachoua, H. 2012. Computer-Assisted Language Learning for Improving Students' Listening Skill. International Conference On Education And Educational Psychology. 69(2012) : 1150-1159.

[11]. Sejdiu, S. 2017. Are listening skills best enhanced through the use of multimedia technology. Digital Education Review. 32(2017): 60-72

[12]. Dirven, R., \& Oakeshott-Taylor, J. 1984. Listening Comprehension (Part I). Language Teaching: The International Abstracting Journal for Language Teachers and Applied Linguistics, 17(4): 326-343.

[13]. Morley, H. J. \& Lawrence, M. S. 1971. The Use of Films in Teaching English as a Second Language. Language Learning, 22(1): 101-3

[14]. Bozorgian, H. 2012. Listening Skill Requires a Further Look into Second/Foreign Language Learning. International Scholarly Research Network. 2012.

[15]. Abdalhamid, F. 2012. Listening Comprehension Strategies Of Arabic-Speaking ESL Learners. Colorado State University. Fort Collins, Colorado.

[16]. Kemmis. and McTaggart.1988. The Action Research Planner. Deakin University, Australia: Deakin University Press

[17]. Creswell,J.W.2001.Qualitative Inquiry and Research design Choosing Among five Traditions. Thousand oaks, CA: Sage Publications. 